\title{
KONSISTENSI PENGGUNAAN ISTILAH GASTROENTERITIS PADA DOKUMEN REKAM MEDIS RAWAT INAP RSUD DR.SOEKARDJO KOTA TASIKMALAYA
}

\author{
Reni Asmaya Lestari' ${ }^{1}$, Ida Wahyuni ${ }^{2}$ \\ 1,2 Poltekkes Kemenkes Tasikmalaya \\ reniasmaya@yahoo.com
}

\begin{abstract}
Every care facilities require special language of communication among officers, in order to achieve an effective and efficient services. The use of the term is the one of the languages in service should provide a common understanding for all officers. The terminology can be diagnostic procedures, surgery or drug therapy. The use of terms that varians in one disease may cause difficulties in the collection of information of morbidity and mortality. The use of terminology gastroenteritis on medical records inpatient in RSUD dr. SoekardjoTasikmalaya City, there are still inconsistent. The purpose of the study to determine the consistency of the use of terminology gastroenteritis in medical records inpatient. This type of research is descriptive with retrospective approach. This research uses simple random sampling from a population of 299 and available a sample of 171. Data collection by observation and review medical records inpatient. The result of the research shows that the use of terminology from 171 documents contained a consistent 43\% and 57\% were inconsistent. Care workers should improve the result of recording so that the information in the medical record higher quality. The need for cooperation among professional health personnel that established communication and good coordination to fill of medical record.
\end{abstract}

Keywords: Consistency, Terminology, Gastroenteritis.

\begin{abstract}
Abstrak
Setiap sarana pelayanan kesehatan membutuhkan bahasa khusus sebagai sarana komunikasi antar petugas, agar tercapai pelayanan yang efektif dan efisien. Penggunaan istilah sebagai salah satu bahasa dalam pelayanan harus memberikan pemahaman yang sama bagi semua petugas. Istilah medis tersebut dapat berupa prosedur diagnosis, terapi bedah atau obat.Penggunaan istilah yang bervariasi dalam satu penyakit dapat menimbulkan kesulitan dalam pengumpulan, perolehan informasi morbiditas dan mortalitas.Penggunaan istilah medis gastroenteritis pada dokumen rekam medis rawat inap RSUD dr.Soekardjo Kota Tasikmalaya masih ada yang tidak konsisten. Tujuan penelitian ini untuk mengetahui konsistensi penggunaan istilah medis gastroenteritis pada dokumen rekam medis rawat inap.Jenis penelitian ini adalah deskriptif dengan pendekatan retrosektif. Pengambilan sampel menggunakan Simple Random Sampling dari populasi 299 dan diperoleh sampel sebanyak 171. Pengumpulan data dengan cara observasi dan telaah dokumen rekam medis rawat inap. Hasil penelitian menunjukan bahwa penggunaan istilah medis dari 171 dokumen terdapat $43 \%$ yang konsisten dan $57 \%$ yang tidak konsisten. Petugas pelayanan hendaknya memperbaiki hasil pencatatan, agar informasi yang ada dalam dokumen rekam medis lebih berkualitas. Perlu adanya kerja sama antar profesi tenaga kerja di rumah sakit, supaya terjalin komunikasi dan koordinasi yang baik dalam mengisi dokumen rekam medis.
\end{abstract}

Kata Kunci: Konsistensi, Istilah Medis, Gastroenteritis

\section{PENDAHULUAN}

Sistem Kesehatan (health system) adalah tatanan yang bertujuan tercapainya derajat kesehatan yang bermutu tinggi dan merata, melalui upaya-upaya yang dilaksanakan secara efisien dan berkualitas serta terjangkau (Hatta, 2008:6). Rumah sakit sebagai salah satu fasilitas pelayanan kesehatan merupakan bagian dari sumber daya kesehatan yang sangat diperrlukan dalam mendukung penyelenggaraan upaya kesehatan (Hosizah, 2014:110-141).

Penyelenggaraan pelayanan Rumah Sakit salah satunya adalah unit rekam medis. Menurut Peraturan Menteri Kesehatan Republik Indonesia No.269/ MENKES/PER/III/2008 Pasal 1 yang dimaksud dengan Rekam Medis adalah berkas yang berisikan catatan dan dokumen tentang identitas pasien, 
pemeriksaan, pengobatan, tindakan dan pelayanan lain yang telah diberikan kepada pasien. Dokumen yang terdapat dalam rekam medis merupakan catatan dokter, dokter gigi dan/atau tenaga kesehatan tertentu, laporan hasil pemeriksaan penunjang, catatan observasi dan pengobatan harian dan semua rekaman, baik berupa foto radiologi, gambar pencitraan (imaging), dan rekaman elektro diagnosis. Rekam medis dalam pembuatannya juga dijelaskan dalam Pasal 2 ayat (1) bahwa Rekam medis harus di buat secara tertulis, lengkap, dan jelas (Hosizah, 2014:596-597).

Penyelenggara pelayanan kesehatan harus mampu menjalankan sistem pelayanannya secara efisien dan efektif, dengan memanfaatkan data medis dan ilmu pengetahuan yang mutakhir. Hal tersebut dalam upaya menghasilkan produk pelayanan yang memenuhi standar dan kebutuhan konsumen sesuai dengan perkembangan zaman. Agar upaya tersebut bisa berhasil tercapai maka pelayanan kesehatan harus memiliki terminologi medis penyakit dan kesehatan yang seragam di bidang prosedur diagnosis, terapi medis bedah ataupun obat, yang dimengerti dan digunakan secara bersama. Sehingga dapat dengan mudah diintegrasikan ke rekam medis manual ataupun berbasis komputer.

Seiring berkembangnya penggunaan istilah medis dalam pelayanan kesehatan yang didukung dengan beragamnya latar belakang pendidikan tenaga medis yang bervariasi, maka penggunaan istilah medis pun menjadi bervariasi. Selama bertahun-tahun, banyak penyakit dan prosedur diperkenalkan dengan istilah yang berbeda-beda. Penggunaan lebih dari satu perolehan istilah untuk penyakit yang sama, menyulitkan dalam pengumpulan dan perolehan informasi morbiditas dan mortalitas yang akurat dan tepat (Hatta, 2008:130-131).

Berkaitan dengan hal tersebut sering kali ditemukan berbagai istilah medis yang berbeda untuk satu maksud yang sama, dalam hal ini kasus gastroenteritis. Gastroenteritis merupakan suatu penyakit yang sering ditemukan di berbagai belahan dunia, terutama daerah tropis. Penyakit ini menyerang masyarakat pada semua kelompok usia dan merupakan penyebab utama morbiditas dan mortalitas. Dalam Profil Kesehatan Indonesia 2010, menurut Daftar Tabulasi Dasar (DTD) pola 10 penyakit terbanyak pada pasien rawat inap di rumah sakit tahun 2010 menunjukan bahwa kasus terbanyak merupakan penyakit gastroenteritis dengan jumlah total kasus sebesar 71.889 kasus. Pada kasus yang sama di RSUD
dr.Soekardjo kasus terbanyak terdapat pada periode triwulan IV tahun 2014 dengan jumlah 299 kasus dari 883 kasus.

Pada hasil pencatatan tenaga medis pemberi pelayanan,tidak sedikit dijumpai maksud dari catatan medis adalah Gastroenteritis, tetapi dengan istilah yang tertulis dalam dokumen rekam medis berbeda. Sehingga petugas rekam medis membutuhkan waktu yang lama untuk dapat menentukan diagnosis yang sebenarnya.Upaya menghindari hal itu terjadi, rekam medis pasien dilakukan kegiatan assembling dengan analisis kualitatif dokumen rekam medis.Kegiatan ini dimaksudkan untuk meminimalisir catatan yang tidak konsisten.Namun, dalam pelaksanaannya petugas rekam medis cenderung hanya melaksanakan analisis kuantitatif dan belum ke arah analisis kualitatif.Penyebabnya karena terbatasnya waktu atau keterampilan dari petugas rekam medis itu sendiri. Padahal, semakin tingginya tingkat sarana pelayanan kesehatan yang ada, kebutuhan akan analisis kualitatif menjadi semakin kompleks (Hatta, 2008).

Dalam pelaksanaannya, sebelum menyimpan dokumen rekam medis ke dalam rak penjajaran (filling), petugas rekam medis sering kurang jeli dalam menganalisis dokumen rekam medis.Akibatnya, bila dokumen rekam medis diperiksa kembali sering terdapat kekuranglengkapan data atau informasi yang vital. Dari sudut pertanggungjawaban secara hukum, ketidakcermatan dalam penganalisisan dapat berakibat fatal, baik terhadap pasien, instansi maupun sebagai ancaman kelalaian terhadap pihak pengisi. Mengingat data atau informasi harus lengkap, maka penggunaan istilah medis pun merupakan suatu hal yang penting, agar tidak terjadi perbedaan persepsi atau pendapat para pemberi pelayanan kesehatan di suatu instansi serta berefek pada tidak akuratnya data morbiditas yang dihasilkan.

studi pendahuluan yang telah dilakukan peneliti di RSUD dr.Soekardjo Kota Tasikmalaya tanggal 11 Februari 2015 diperoleh data dari ruang rekam medis, diketahui bahwa dalam penggunaan istilah medis gastroenteritis masih ada yang belum menggunakan istilah medis yang konsisten dan sesuai dengan ICD10. Dokumen rekam medis dikatakan konsisten apabila pengisian dan penggunaan istilah medis pada dokumen sesuai dengan penggunaan maksud istilah medis pada ICD-10.Begitupun sebaliknya, apabila pengisian dan penggunaan istilah medis pada dokumen tidak sesuai dengan penggunaan istilah medis pada ICD-10 maka dikatakan tidak konsisten.Hal tersebut diketahui 
bahwa dari 10 dokumen rekam medis dengan kasus gastroenteritis terdapat 6 dokumen yang penggunaan istilah medisnya tidak sesuai dengan istilah medis pada ICD-10.

Mengingat rekaman medis pasien sebagai bukti hasil pelayanan yang diberikan terhadap pasien mencakup informasi standar yang harus lengkap dan berkualitas, maka penelitian ini dilakukan dalam rangka mengetahui Konsistensi Penggunaan Istilah Gastroenteritis pada Dokumen Rekam Medis Rawat Inap Rumah Sakit Umum Daerah dr.Soekardjo Kota Tasikmalaya.

\section{METODE}

Penelitian ini bersifat deskriptif yaitu penelitian yang dimaksudkan untuk memotret konsistensi penggunaan istilah gastroenteritis, dengan menggali informasi dengan pendekatan retrospektif. Populasi dalam penelitian ini berupa dokumen rekam medis rawat inap kasus gastroenteritis di RSUD dr.Soekardjo triwulan IV tahun 2014 sebanyak 299 dokumen. Dengan teknik Random Sederhana (Simple Random Sampling) didapatkan sampel sebanyak 171 dokumen. Variabel penelitian ini yaitu konsistensi penggunaan istilah medis gastroenteritis pada dokumen rekam medis rawat inap. Teknik pengumpulan data yaitu Observasi dengan instrumen yang digunakan adalah lembar obeservasi. Analisis data dengan univariat dalam bentuk tabel distribusi frekuensi.

\section{HASIL}

\section{Penggunaan Istilah Medis Penyakit Gastroen- teritis}

Berdasakan hasil penelitian di RSUD dr.Soekardjo Kota Tasikmalaya mengenai konsistensi penggunaan istilah medis gastroenteritis pada dokumen rekam medis rawat inap didapatkan data dengan beberapa penggunaan istilah yang berbeda-beda seperti pada tabel berikut:
Tabel 1 Penggunaan Istilah Medis Gastroenteritis $(n=171)$

\begin{tabular}{|c|c|c|c|c|c|}
\hline \multirow[b]{2}{*}{ No } & \multirow[b]{2}{*}{ Istilah } & \multicolumn{3}{|c|}{$\begin{array}{l}\text { Triwulan IV Ta- } \\
\text { hun } 2014 \\
\end{array}$} & \multirow[b]{2}{*}{ Jml } \\
\hline & & $\begin{array}{l}\text { Bu- } \\
\text { lan } \\
10\end{array}$ & $\begin{array}{l}\text { Bu- } \\
\text { lan } \\
11\end{array}$ & $\begin{array}{l}\text { Bu- } \\
\text { lan } \\
12\end{array}$ & \\
\hline 1 & Gastroenteritis & 5 & 1 & 4 & 10 \\
\hline 2 & Gastroenteritis Akut & 4 & 1 & 1 & 6 \\
\hline 3 & GE & 10 & 6 & 5 & 21 \\
\hline 4 & GEA & 17 & 11 & 9 & 37 \\
\hline 5 & Diare & 23 & 10 & 13 & 46 \\
\hline 6 & Diare Akut & 18 & 3 & 5 & 26 \\
\hline 7 & Diare Kronis & 14 & 3 & 8 & 25 \\
\hline \multicolumn{2}{|c|}{ Jumlah } & 91 & 35 & 45 & 171 \\
\hline
\end{tabular}

Berdasarkan tabel 1 terdapat tujuh istilah medis yang dipergunakan untuk kasus gastroenteritis yaitu Gastroenteritis, Gastroenteritis Akut, GE, GEA, Diare, Diare Akut dan Diare Kronis dan diketahui pula untuk penggunaan istilah yang konsisten (Gastroenteritis, Gastroenteritis Akut, GE dan GEA) dan ada penggunaan istilah medis gastroenteritis yang tidak konsisten (Diare, Diare Akut dan Diare Kronis).

\section{Konsistensi Penggunaan Istilah Medis Gastro- enteritis}

Berdasarkan penelitian yang telah dilakukan dari hasil tabel 1 dengan jumlah 171 dokumen rekam medis, maka didapatkan data seperti tabel berikut ini:

Tabel 2 Distribusi Frekuensi Konsistensi Penggunaan Istilah Medis Gastroenteritis

\begin{tabular}{|c|c|c|c|c|c|c|c|c|c|}
\hline \multirow{3}{*}{ No } & \multirow{3}{*}{$\begin{array}{c}\text { Penggu- } \\
\text { naan } \\
\text { Istilah }\end{array}$} & \multicolumn{6}{|c|}{ Triwulan IV Tahun 2014} & \multirow{2}{*}{\multicolumn{2}{|c|}{ Jumlah }} \\
\hline & & \multicolumn{2}{|c|}{ Bulan 10} & \multicolumn{2}{|c|}{ Bulan 11} & \multicolumn{2}{|c|}{ Bulan 12} & & \\
\hline & & n & $\mathbf{P}$ & $\mathrm{n}$ & $\mathbf{P}$ & $n$ & $\mathbf{P}$ & $\mathrm{n}$ & $\mathbf{P}$ \\
\hline 1 & Konsisten & 36 & $40 \%$ & 19 & $54 \%$ & 19 & $42 \%$ & 74 & $43 \%$ \\
\hline 2 & $\begin{array}{l}\text { Tidak } \\
\text { Konsisten }\end{array}$ & 55 & $60 \%$ & 16 & $46 \%$ & 26 & $58 \%$ & 97 & $57 \%$ \\
\hline & Jumlah & 91 & $100 \%$ & 35 & $100 \%$ & 45 & $100 \%$ & 171 & $100 \%$ \\
\hline
\end{tabular}


Dari data pada tabel 2 dapat diketahui bahwa konsistensi penggunaan istilah medis gastroenteritis di RSUD dr.Soekardjo dari 171 dokumen rekam medis rawat inap terdapat 74 dokumen rekam medis (43\%) yang konsisten dan 97 dokumen rekam medis (57\%) yang tidak konsisten penggunaan istilah medisnya. Dimana, tingkat kekonsistenan penggunaan istilah medis pada dokumen rekam medis yang paling tinggi terdapat pada bulan November dengan jumlah 19 dokumen (54\%) dari 35 dokumen rekam medis, sedangkan tingkat kekonsistenan penggunaan istilah medis pada dokumen rekam medis yang paling rendah terdapat pada bulan Oktober dengan jumlah 36 dokumen (40\%) dari 91 dokumen rekam medis. Selain itu, tingkat ketidakkonsistenan penggunaan istilah medis pada dokumen rekam medis yang paling tinggi terdapat pada bulan Oktober dengan jumlah 55 dokumen (60\%) dari 91 dokumen rekam medis, sedangkantingkat ketidakkonsistenan penggunaan istilah medis pada dokumen rekam medis yang paling rendah terdapat pada bulan November dengan jumlah 16 dokumen (46\%) dari 35 dokumen rekam medis.

\section{PEMBAHASAN}

\section{Penggunaan Istilah Medis Gastroenteritis}

Penyelenggara pelayanan kesehatan harus mampu menjalankan sistem pelayanannya secara efisien dan efektif, dengan memanfaatkan data medis dan ilmu pengetahuan yang mutakhir.Hal tersebut dalam upaya menghasilkan produk pelayanan yang memenuhi standar dan kebutuhan konsumen sesuai dengan perkembangan zaman.Agar upaya tersebut bisa berhasil tercapai maka pelayanan kesehatan harus memiliki terminologi medis penyakit dan kesehatan yang seragam di bidang prosedur diagnosis, terapi medis bedah ataupun obat, yang dimengerti dan digunakan secara bersama sehingga dapat dengan mudah diintegrasikan ke rekam medis manual ataupun berbasis komputer. Selama bertahuntahun, banyak penyakit dan prosedur diperkenalkan dengan istilah yang berbeda-beda. Penggunaan lebih dari satu perolehan istilah untuk penyakit yang sama, menyulitkan dalam pengumpulan dan perolehan informasi morbiditas dan mortalitas yang akurat dan tepat (Hatta, 2008).

Berdasarkan observasi pada penelitian yang dilakukan pada tanggal 12-18 Mei 2015 di Rumah Sakit Umum Daerah dr.Soekardjo Kota Tasikmalaya diketahui bahwa dalam pengisian formulir-formulir pada dokumen rekam medis sudah ada ketentuan yang mengatur tata cara pengisian dokumen rekam medis pasien berupa Standar Operasional Prosedur (SOP). Pelaksanaan pengisian item informasi pada formulir dalam dokumen rekam medis khususnya pasien rawat inap telah mengikuti SOP, salah satunya lembar masuk dan keluar (CM 1). Namun dari hasil observasi ditemukan ketidaksesuaian pelaksanaan kegiatan pengisian dengan SOP, khususnya mengenai pengisian diagnosis utama. Menurut Hatta (2008:170) Diagnosis Utama adalah kondisi yang ditentukan setelah penelaahan sebagai paling bertanggung jawab akan kedatangan pasien ke rumah sakit atau rumah perawatan untuk memperoleh perawatan. Dalam SOP No. 38/CM/2010 tentang Pengisian Lembar Masuk dan Keluar (CM 1) pada prosedur pengisian diagnosis utama poin 4.21 bahwa Diagnosa utama adalah penyakit yang selama dirawat membutuhkan perawatan paling lama atau lebih intensif atau lebih membutuhkan biaya, sebaiknya tidak menulis symptom dan sign sebagai diagnosis utama. Bila gejala-gejala dari diagnosis utama perlu dicatat, tulislah dalam kurung dibelakang diagnosis utama, misal : GE Akut (dehidrasi asidosis).

Berkaitan dengan hal tersebut ditemukan ada tujuh istilah medis yang dipergunakan untuk penyakit gastroenteritis, meliputi Gastroenteritis, Gastroenteritis Akut, GE, GEA, Diare, Diare Akut dan Diare Kronis. Dimana, kondisi gejala yaitu seperti Diare, Diare Akut dan Diare Kronis sebaiknya tidak ditulis sebagai diagnosis utama, karena kondisi gejala tersebut tidak sesuai dengan SOP Pengisian Lembar Masuk dan Keluar. Bilamana hal itu terjadi maka, penggunaan lebih dari satu istilah medis untuk satu penyakit yang sama akan menyulitkan dalam pengumpulan, perolehan dan pengolahan informasi morbiditas dan mortalitas yang akurat dan tepat (Hatta, 2008:131).

Berdasarkan hasil wawancara yang dilakukan di RSUD dr.Soekardjo dengan petugas rekam medis diketahui bahwa penyebab penggunaan istilah yang berbeda-beda yaitu pelaksanaan analisis kualitatif di RSUD dr.Soekardjo belum dilaksanakan.Hal tersebut disebabkan karena kurangnya Sumber Daya Manusia (SDM) di bagian assembling. Selain itu, jika analisis kualitatif dilakukan dalam waktu satu hari tidak akan cukup karena melakukan analisis kualitatif terhadap satu DRM akan memakan waktu yang lama. Penyebab lainnya yaitu kurangnya komunikasi antara petugas rekam medis dengan dokter yang 
merawat dalam mengisi dokumen rekam medis, karena diagnosis utama tidak seharusnya diisi dengan gejala. Penyebab selanjutnya belum adanya pedoman pembakuan istilah medis untuk satu kasus penyakit yang sama, sehingga terjadi perbedaan istilah untuk satu kasus penyakit yang sama.

\section{Konsistensi Penggunaan Istilah Medis Gastro- enteritis}

Konsisten adalah tetap (tidak berubah-ubah), taat asas, selaras, sesuai.Konsistensi adalah ketetapan dan kemantapan (Kamus Besar Bahasa Indonesia, 2005:589). Konsistensi berarti kesesuaian berbagai bagian satu sama lainnya dan sebagai keseluruhan. Seperti telah disebutkan, pernyataan diagnosis di rumah sakit harus konsisten sejak admission sampai discharge.Pernyataan diagnosis hendaknya juga menunjukan konsistensi antara bagian-bagian catatan medis.

Berdasarkan hasil penelitian yang dilakukan pada tanggal 12-18 Mei 2015 mengenai Konsistensi Penggunaan Istilah Medis Gastroenteritis Pada Dokumen Rekam Medis Rawat Inap RSUD dr.Soekardjo Kota Tasikmalaya ditemukan adanya penggunaan istilah medis yang tidak konsisten.Hal tersebut, terlihat dari banyaknya dokumen rekam medis rawat inap yang penggunaan istilah medis diagnosis utamanya tidak konsisten sebanyak 57\% dari 171 dokumen rekam medis. Dimana, tingkat kekonsistenan penggunaan istilah medis pada dokumen rekam medis yang paling tinggi terdapat pada bulan November dengan jumlah 54\% dari 35 dokumen rekam medis, sedangkan tingkat kekonsistenan penggunaan istilah medis pada dokumen rekam medis yang paling rendah terdapat pada bulan Oktober dengan jumlah 40\% dari 91 dokumen rekam medis. Selain itu, tingkat ketidakkonsistenan penggunaan istilah medis pada dokumen rekam medis yang paling tinggi terdapat pada bulan Oktober dengan jumlah $60 \%$ dari 91 dokumen rekam medis, sedangkan tingkat ketidakkonsistenan penggunaan istilah medis pada dokumen rekam medis yang paling rendah terdapat pada bulan November dengan jumlah $46 \%$ dari 35 dokumen rekam medis.

Penggunaan istilah medis yang tidak konsisten tentu akan menyulitkan petugas dalam penentuan kode diagnosis, pemberian tindakan kepada pasien, pengumpulan data pelayanan dan pengolahan data pelayanan. Serta berpengaruh pada keperluan penelitian dan pendidikan karena informasi yang dihasilkan tidak konsisten atau belum lengkap. Hal tersebut, mengacu pada Peraturan Menteri Kesehatan RI Nomor 269/MENKES/PER/III/2008 BAB V Pasal 13 Ayat (1) tentang Pemanfaatan Berkas Rekam Medis bahwa Pemanfaatan rekam medis dapat dipakai sebagai, pemeliharaan kesehatan dan pengobatan pasien; alat bukti dalam proses penegakan hukum, disiplin kedokteran dan kedokteran gigi serta penegakkan etika kedokteran dan etika kedokteran gigi; keperluan pendidikan dan penelitian; dasar pembayaran biaya pelayanan kesehatan; dan data statistik kesehatan (UU Praktik Kedokteran, 2011:105). Selain itu, menurut Hatta (2008:140) tentang Peraturan Morbiditas bahwa Pengodean morbiditas sangat bergantung pada diagnosis yang ditetapkan oleh dokter yang merawat pasien atau yang bertanggung jawab menetapkan kondisi utama pasien, yang akan dijadikan dasar pengukuran statistik morbiditas. Proses pengodean diagnosis yang penting adalah petugas koding harus mengkaji lebih teliti rekam medis pasien. Berkaitan hal tersebut, apabila dokumen rekam medis yang akan di koding dalam keadaan tidak lengkap dan kerap tidak tepat waktu maka akan memakan waktu yang lama dalam pengodean untuk satu dokumen rekam medis.

Menurut Hatta (2008:350) Upaya untuk mencegah informasi tidak lengkap atau kurang lengkap dengan melakukan kegiatan analisis rekam kesehatan (RK). Kegiatan ini dibedakan dalam dua jenis yaitu analisis kuantitatif dan kualitatif yang dilakukan di bagian assembling.Namun, kebanyakan petugas analisis RK hanya sampai melaksanakan analisis kuantitatif dan belum ke arah analisis kualitatif.Penyebabnya karena terbatasnya waktu atau keterampilan diri. Padahal, semakin tingginya tingkat sarana pelayanan kesehatan yang ada, kebutuhan akan analisis kualitatif menjadi semakin kompleks. Selain itu, tujuan analisis kualitatif adalah demi terciptanya isi rekam medis yang terhindar dari masukan yang tidak ajeg atau taat asas (konsisten) maupun pelanggaran terhadap rekaman yang berdampak pada hasil yang tidak akurat dan tidak lengkap. Kebijakan yang berlaku di RSUD dr.Soekardjo mengenai analisis RK terdapat pada Pedoman Penyelenggaraan Rekam Medis (2011:31) No. 4.3.1 tentang Assembling atau Perakitan Rekam Medis bahwa Setiap berkas rekam medis yang kembali dari ruang perawatan ke rekam medis harus disusun sesuai ketentuan yang berlaku di Rumah Sakit Umum Daerah Tasikmalaya, dicek 
kelengkapan baik isi maupun lembaran-lembaran yang harus ada (analisis kuantitatif dan kualitatif). Namun, kebijakan tersebut belum dapat sepenuhnya dilaksanakan khususnya mengenai analisis kualitatif.

Selain upaya analisis RK, adapun upaya untuk bisa mengatasinya yaitu kerjasama.Menurut Sabarguna dan Sumarni (2003:4) Sejarah kedokteran dan kesehatan yang telah secara turun temurun dan alamiah menunjukkan perlunya kerjasama, saling tergantung dan saling menghormati profesi merupakan modal yang sudah solid dan menguntungkan. Sehingga perlu adanya kerja sama antara dokter dan perawat supaya terjalin komunikasi dan koordinasi yang baik dalam mengisi dokumen rekam medis, khususnya dalam mengisi diagnosis pasien agar konsisten. Perlunya kerjasama antara dokter atau tenaga medis lain dengan tenaga rekam medis supaya terjalin komunikasi dan koordinasi yang baik agar dalam pengisian lembaran-lembaran pada dokumen rekam medis, khususnya diagnosis utama dapat terbaca, informasinya jelas, konsisten dan terhindar dari ketidaklengkapan.

\section{SIMPULAN}

Berdasarkan hasil penelitian yang dilakukan pada tanggal 12-18 Mei 2015 di Rumah Sakit Umum Daerah dr.Soekardjo Kota Tasikmalaya mengenai Konsistensi Penggunaan Istilah Medis Gastroenteritis Pada Dokumen Rekam Medis Rawat Inap diketahui ada 171 dokumen rekam medis dengan kasus gastroenteritis. Setelah dilakukan penelitian dapat diperoleh simpulan sebagai berikut :

1. Penggunaan istilah medis gastroenteritis pada dokumen rekam medis rawat inap diperoleh tujuh istilah yang dipergunakan untuk kasus gastroenteritis, diantaranya Gastroenteritis, Gastroenteritis Akut, GE, GEA, Diare, Diare Akut dan Diare Kronis.

2. Tingkat konsistensi penggunaan istilah medis gastroenteritis pada dokumen rekam medis rawat inap triwulan IV tahun 2014 dari jumlah dokumen rekam medis sebanyak 171 dokumen diketahui penggunaan istilah medis gastroenteritis yang konsisten sebanyak $43 \%$. Sedangkan, penggunaan istilah medis gastroenteritis yang tidak konsisten yaitu sebanyak 57\%. Dimana, tingkat kekonsistenan penggunaan istilah medis yang paling tinggi terdapat pada bulan November dengan jumlah
$54 \%$ dari 35 dokumen,sedangkantingkat kekonsistenan penggunaan istilah medis yang paling rendah terdapat pada bulan Oktober dengan jumlah $40 \%$ dari 91 dokumen.Selain itu, tingkat ketidakkonsistenan penggunaan istilah medis yang paling tinggi terdapat pada bulan Oktober dengan jumlah 60\% dari 91 dokumen, sedangkantingkat ketidakkonsistenan penggunaan istilah medis yang paling rendah terdapat pada bulan November dengan jumlah $46 \%$ dari 35 dokumen

\section{DAFTAR PUSTAKA}

Arikunto, Suharsimi. (2010). Procedur Penelitian: Suatu Pendekatan Praktik (ed. rev.). Jakarta: Rineka Cipta. Hal.3

Departemen Pendidikan Nasional. (2005). Kamus Besar Bahasa Indonesia ( ${ }^{r d}$ ed.). Jakarta: Balai Pustaka. Hal.589

Depkes.(2006). Pedoman Penyelenggaraan dan Prosedur Rekam Medis Rumah Sakit Di Rumah Sakit. Jakarta: Depkes RI. Hal.13,45-46,80

Dorland, W.A.N. (2008). Kamus Saku Kedokteran Dorland (28 thed.). (Albertus et al.,.Penerjemah). Jakarta: Buku Kedokteran EGC. Hal.466

Hatta, G.R. (2008). Pedoman Manajemen Informasi Kesehatan Di Sarana Pelayanan Kesehatan. Jakarta: Universitas Indonesia (UI-Press). Hal.6,92-95,130-131,354

Hosizah.(2014). Kumpulan Peraturan Perundangan Rekam Medis dan Informasi Kesehatan (Manajemen Informasi Kesehatan). Yogyakarta: aptiRMIK Press. Hal.569-600

Huffman, EK. (1994). Health Information Management. (Erkadius, Penerjemah) Berwyn: Phsyician Record Company. Hal.25-31

Nasir, Abd. et al. (2011). Buku Ajar Metodologi Penelitian Kesehatan: Konsep Pembuatan Karya Tulis dan Thesis untuk Mahasiswa Kesehatan. Yogyakarta: Nuha Medika. Hal.187249

Notoatmodjo, Soekidjo.(2010). Metodologi Penelitian Kesehatan. Jakarta: Rineka Cipta. Hal.27,103,111,137 
Nuryati.(2011). Terminologi Medis Pengenalan Istilah Medis. Yogyakarta: Quantum Sinergis Media. Hal.1-28

Ramdani, Taufik. (2013). Tinjauan Konsistensi Penggunaan Istilah Medis Penyakit Gastritis pada Dokumen Rekam Medis Rawat Inap Di Rumah Sakit Umum Daerah (RSUD) Kota Banjar Periode Triwulan I Tahun 2013. Karya Tulis Ilmiah PIKES POLTEKKES TASIKMALAYA. Tasikmalaya: tidak di terbitkan. Hal.32
Rustiyanto, Ery. (2009). Etika Profesi Perekam Medis \& Informasi Kesehatan. Yogyakarta: Graha Ilmu. Hal.5-8

Sabarguna dan Sumarni.(2003). Sumber Daya Manusia Rumah Sakit. Yogyakarta: Konsorsium. Hal. 4

Sugiyono. (2009). Metode Penelitian Kuantitatif Kualitatif Dan R\&D. Bandung: Alfabeta. Hal.145-14 